\title{
BUYING LOCAL? WHO, WHAT, WHY?
}

\author{
CARMen Simona Dumitrescu \\ Banat University of Agricultural Sciences and Veterinary Medicine "King Michael I of \\ Romania" from Timisoara, \\ Faculty of Agricultural Management \\ Timisoara, Calea Aradului 119, 300645 \\ carmen02dumitrescu@gmail.com
}

\begin{abstract}
The National Rural Development Programme for the period 2014-2020 through its priorities and interest domains refers to local products and short supply chains in order to increase the competitiveness of local primary producers and the added value of agro-alimentary and non-alimentary products, and to promote on local markets through short supply chains, producers groups and organizations. Local food can have many benefits for the actors involved in the short supply chain, more precisely producers, middlemen and consumers, but also for the local economy in its all.

The local market from Timisoara is provided by many local producers from rural area that are producing and selling a varied number of alimentary and non-alimentary products. The case study is oriented towards the brief analysis of alimentary local products' consumers and its aim is to realise a profile of local food consumer through underlining the aspects regarding the reasons why they are buying such products, the place from where they buy, but also aspects regarding the implications and benefits the consume can have.
\end{abstract}

Keywords: local food, short supply chains, consumer, benefits

\section{INTRODUCTION}

The term local food is widely used but there are no precise standards to define this term. In many cases, the consumers define local food as food grown within a county or coming from neighbouring areas (HARRIS, 2000).

Today many people are concerned about their food, about the place where it is produced and technologies used to obtain the food products. But there are also others food characteristics like freshness, quality, environment impact that are in people's concern.

The interest for local food is growing and consumers decide to buy local due to a variety of reasons, but mainly due to perceived nutritional superiority, health benefits, advantages for local economy and also helping protecting the environment (DUMITRESCU, 2005, ZEPEDA, 2006).

Local food quality is the result of the combination of many quality characteristics, some of which are place- related (ARFINI ET AL., 2012).

\section{MATERIAL AND METHOD}

The case study is based on questionnaires applied in two markets from Timișoara. The markets were choose due to the fact that here the local producers from around the city come and sell their products every day, not only in some days as it is the case of the mobile market.

We applied 100 questionnaires, 50 for each market in the period February - March 2017. In choosing the persons to apply the questionnaires we use the random sample and the respondents were not rewarded. The questionnaire had 12 questions, from which 7 
questions have fixed answers and the respondents have to mark the answer suitable for them and 5 questions are with open answer.

\section{RESULTS}

The buyers of local food were asked at the beginning of the interview if they are also consumers and $100 \%$ said they are consumers of local food. So, they were asked to offer the answers to the questions only thinking at their only individual not at their household.

Asking the buyers to define the local food, the majority (76\%) of them defined local food as food which is produced in the area they live, but no references were given to the area delimitations. A part of them (7\%) associate local food with food produced in Romania and the percentage of 4 buyers considered local food only if the village where it was produced was marked on the label, for example cabbage from Belint, watermelon from Gottlob etc. a number of 5 consumers said there must be a definition for local food in the legislation but they don't know it and $8 \%$ of buyers sais local food means food produced in the areas very closed to the city.

From the persons who answered to the questions, $73 \%$ were women, while only $27 \%$ were men. Referring to the age, there were five age classes: 15-24 years, 25-34, 35-44, 45-60, over 60 years old. The persons younger than 15 years old were not taken into consideration due of fact that they were accompanying older persons to the market, usually their parents or close relatives. The number of respondents for each class can be observed in Figure 1.

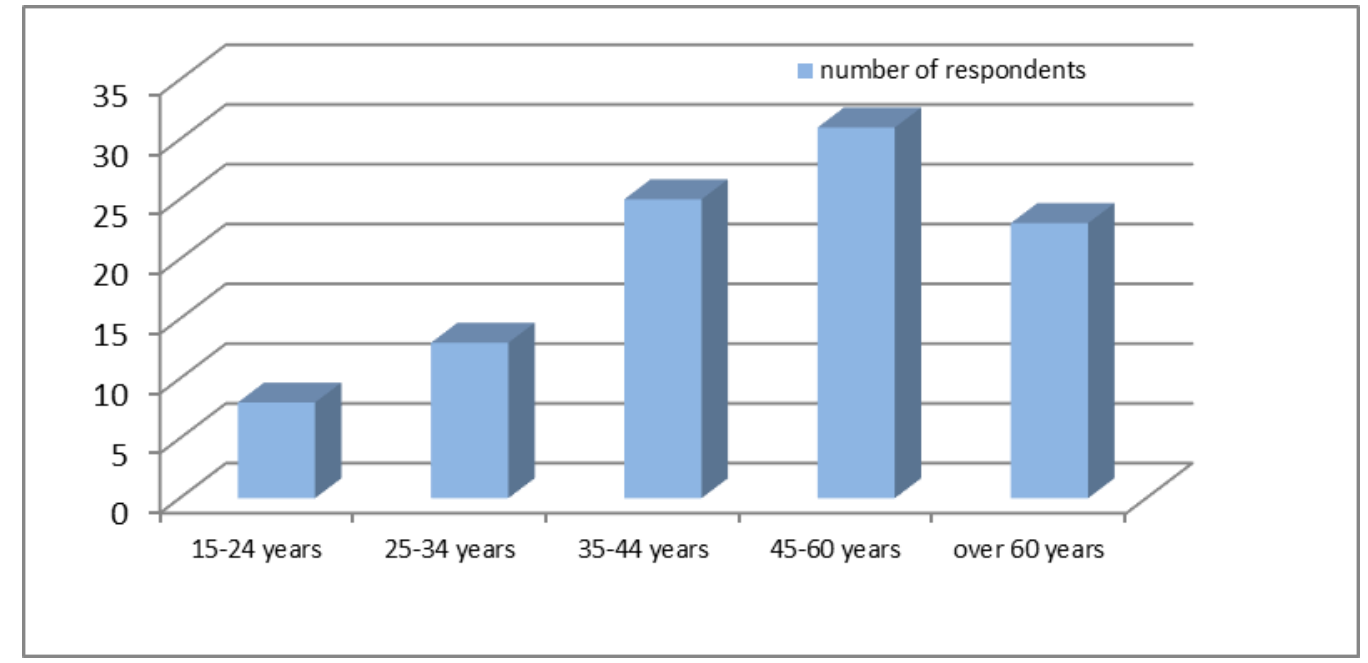

Figure 1. Respondents age classes

While asking if all the food products are local, the largest number of consumers buys only a part of the food products as local because of the seasonality and limited range of products as shown in Figure 2. 


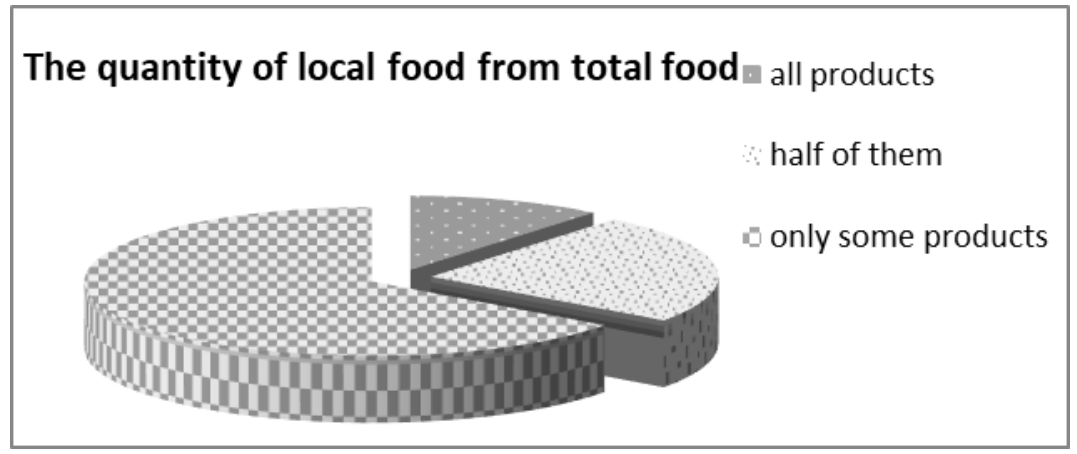

Figure 2. The quantity of local food from total food bought

As it can be seen in Figure 3, the reasons for which the consumers are buying local products are different. There were 5 predefined answers and one where the consumers were asked to specify their reasons at this item. There was no specified number of marks related to the reasons for buying local food.

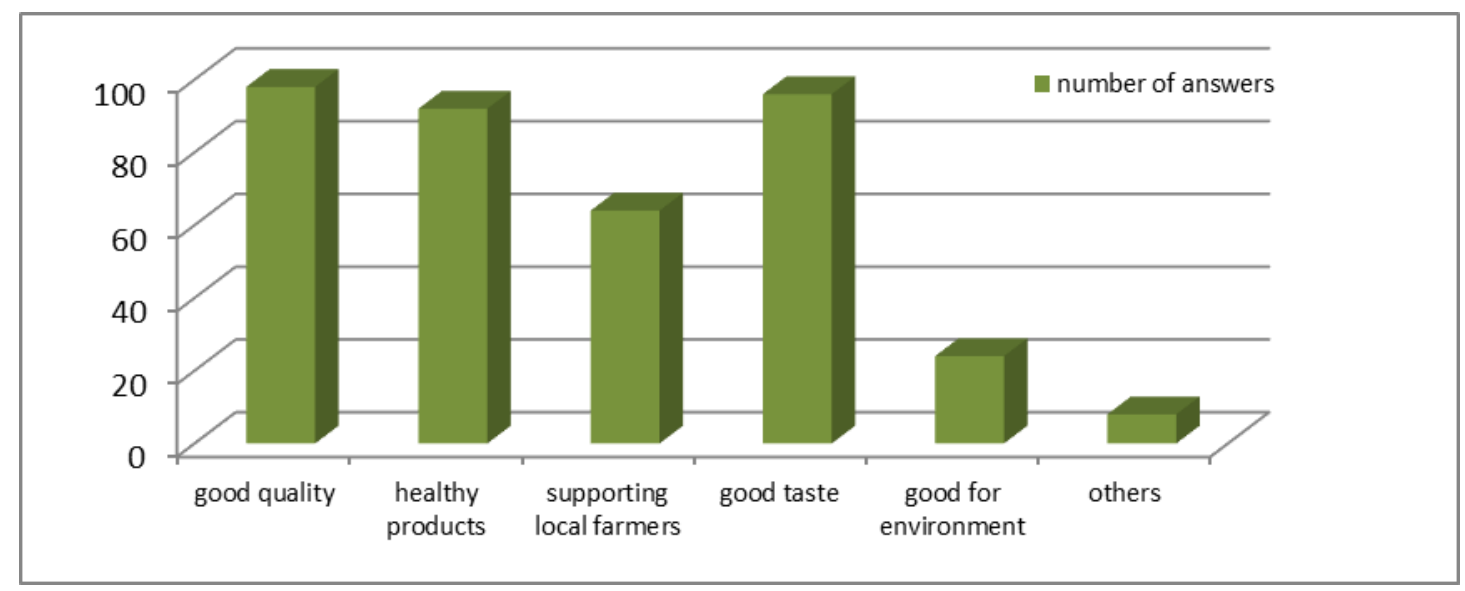

Figure 3. Reasons to buy local food

The questionnaires were applied in the markets, but there was also some interest in seeing all the places the consumers buy local food so there were predefined 6 product class or type, more precisely fruits, vegetables, meat, dairy and eggs, bakery products and others (Figure 4).

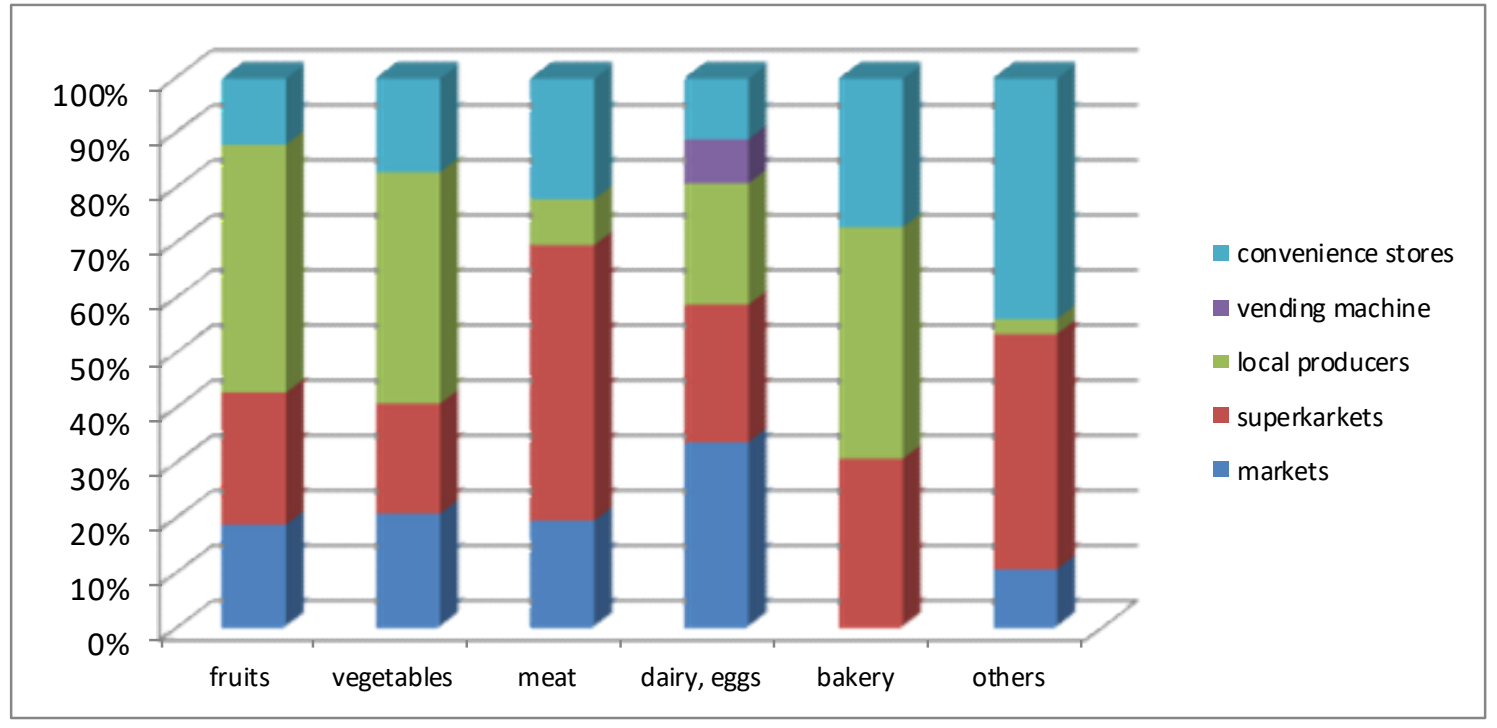

Figure 4. Places the consumers buy local food 
For fruits the answers were divided between supermarkets for the fruits that are not cultivated in our area, local producers that are selling also on the internet and making delivery just to the customers' address, markets. For the vegetables the answers were very close to the ones referring to fruits. Here it must be mentioned according to consumers' answers they are buying from supermarkets because they don't find all the seasons the products they need and also some of them considered that buying from supermarket give them a security feeling cause there is known the producer or even the country the products are coming from. In addition, there must be underlined that the supermarkets active in Timisoara are also occasionally selling local food that comes from local producers and this kind of products is distinctively marked on shelves. The majority of consumers said they buy the meat and meat products from supermarkets due to the variety offered and to the food security control made in supermarkets, while for dairy and eggs the consumers opt also for the vending machines from the city. The bakery products were bought from local bakeries, some of them with tradition on local market, while others products were bought from different stores.

Referring to the benefits local food can have for the local area and community, the respondents opinion were that local food are good for the health and they are high quality products that represents the area. Also, the local food can bring benefits to local community due to the fact that people around the city are involved in their production and selling and also they are good for the environment.

The main reasons for which the consumers don't buy more are the seasonality of the production and sometimes the price, usually when the producers are coming to the market for the first time with early vegetables. Also, here can be found the markets disposal in the city and the fact that if they are going to the supermarkets for shopping they don't go also in the local markets.

But the buyers would be encouraged to buy more local food if there were special spaces arranged for local producers where to have access only registered producers, more mobile markets and if in the supermarkets would find more often local products.

\section{CONCLUSIONS}

Starting from the varied opinions regarding the definition of local food is hard to establish an exact profile for local food consumer.

The local food consumer from Timisoara only buys a part of the food as local products mainly due to the availability of the products. The persons over 35 years old are more concerned on the food they buy and so they try to orient towards local food which they associate with quality and healthy products. The consumers buy local food for their quality, for the taste, also because they consider local food as being healthy food and for supporting the local economy and the environment.

\section{ACKNOWLEDGEMENTS}

This work was published during the project "Internal competition of research projects of Banat's University of Agricultural Sciences and Veterinary Medicine "King Michael I of Romania" from Timişoara, 2015 session, contract no. 2759 - Innovative approach of local food mapping in the context of competitive development of short food supply chains. 


\section{REFERENCES}

Arfini, F., Mancini, M.C., Donati, M. (2012): Local Agri-food Systems in a Global World: Market, Social and Environmental Challenges, Cambridge Scholars Publishing, pp.76.

Dumitrescu, C.S., Bunea, D.M., Andras, M.D., Martin S.C., Marcu, V. (2015): Local products' capitalisation as a contribution to local development, Journal of Biotechnology, no. 208, pp S49-50

Harris, B., Burress D., Mercer S., Oslund P., Rose C. (2000): Kaw Valley Focus Groups on Local and Organic Produce, University of Kansas, IPPBR Report No. 254B RuRal DeVelopment NATiOnal Programme 2014-2020, Romania

ZEPEDA, L., JinghAN, L. (2006): Who buys local food?, Journal of Food Distributon Research, no. 37(3), pp 5-15 